Wilfrid Laurier University

Scholars Commons @ Laurier

Kinesiology and Physical Education Faculty

Publications

Kinesiology and Physical Education

3-2011

\title{
The Role of Enjoyment and Motivational Climate in Relation to the Personal Development of Team Sport Athletes
}

Dany J. MacDonald

Queen's University - Kingston, Ontario

Jean Côté

Queen's University - Kingston, Ontario

Mark Eys

Wilfrid Laurier University, meys@wlu.ca

Janice Deakin

Queen's University - Kingston, Ontario

Follow this and additional works at: https://scholars.wlu.ca/kppe_faculty

\section{Recommended Citation}

MacDonald, Dany J.; Côté, Jean; Eys, Mark; and Deakin, Janice, "The Role of Enjoyment and Motivational Climate in Relation to the Personal Development of Team Sport Athletes" (2011). Kinesiology and Physical Education Faculty Publications. 8.

https://scholars.wlu.ca/kppe_faculty/8

This Article is brought to you for free and open access by the Kinesiology and Physical Education at Scholars Commons@ @aurier. It has been accepted for inclusion in Kinesiology and Physical Education Faculty Publications by an authorized administrator of Scholars Commons @ Laurier. For more information, please contact scholarscommons@wlu.ca. 


\title{
The Role of Enjoyment and Motivational Climate in Relation to the Personal Development of Team Sport Athletes
}

\author{
Dany J. MacDonald and Jean Côté \\ Queen's University \\ Mark Eys \\ Wilfrid Laurier University \\ Janice Deakin \\ Queen's University
}

\begin{abstract}
Sport has been identified as a context in which youth encounter positive and negative experiences. However, relatively little is known about the factors that lead to positive and negative personal development among sport participants. The purpose of this study was to investigate the role of enjoyment and motivational climate on positive and negative personal development of team sport participants. A sample of 510 athletes between the ages of 9 and 19 completed questionnaires on positive and negative personal development, enjoyment, and motivational climate. Stepwise multiple regression analyses examined the effects of enjoyment and motivational climate on the personal development of the athletes. Results demonstrated that positive experiences in sport were most strongly predicted by affiliation with peers, self-referenced competency, effort expenditure, and a task climate. Negative experiences were most strongly predicted by an ego climate and other-referenced competency. Results suggest that creating an environment that encourages peer affiliation and personal achievement can result in the positive personal development of youth sport participants.
\end{abstract}

Sport has been identified as the most popular structured activity for youth participation (Mahoney, Larson, Eccles, \& Lord, 2005). Recently, Guèvremont, Findlay, and Kohen (2008) reported that approximately $76 \%$ of Canadian youth between the ages of 6 and 17 years participated in at least one structured sport activity in the past year. In the United States, it is estimated that approximately $62 \%$ of high school students participated on at least one school or nonschool sport team in the

MacDonald, Côté, and Deakin are with the School of Kinesiology and Health Studies, Queen's University, Kingston, Ontario, Canada. Eys is with Wilfrid Laurier University, Waterloo, Ontario, Canada. 
previous year (Pate, Trost, Levin, \& Dowda, 2000). These data demonstrate that the majority of North American youth have some experience with organized sport.

Weiss and Williams (2004) summarized the reasons why youth participate in sport. They suggested that youth participate for reasons of physical competence/ adequacy (i.e., improve skills, achieve goals), social acceptance (i.e., make new friends, team atmosphere), and enjoyment (i.e., energy release, excitement). These reasons point to the complexity of youth sport involvement, and demonstrate that individual (i.e., enjoyment) and environmental (i.e., team atmosphere) factors are important for understanding participation. Weiss and Williams concluded that participation in youth sport can be enhanced by (a) making sure the sport is enjoyable, (b) creating a task-oriented motivational climate, (c) providing social support, and (d) helping children help themselves. These recommendations highlight enjoyment and motivational climate as critical factors for prolonged participation of youth in sport. The following paragraphs elaborate on the relationship between enjoyment, motivational climate and youth sport.

Enjoyment is consistently associated with continued sport participation (Scanlan, Carpenter, Schmidt, Simons, \& Keeler, 1993; Scanlan, Stein, \& Ravizza, 1989; Weiss, Kimmel, \& Smith, 2001; Wiersma, 2001). To explain why youth commit to sport, Scanlan and colleagues (Scanlan et al., 1989; 1993) developed the sport commitment model. They argued that sport commitment is influenced by five constructs. Four of these constructs-enjoyment, personal investment, social constraints, and involvement opportunities_-were positively associated with commitment, while involvement alternatives were negatively related to sport commitment. Results of their analyses pointed to enjoyment as the most important component linked to youth's commitment to sports. Subsequent work by Weiss et al. (2001) extended the sport commitment model (Scanlan et al., 1993) by including enjoyment as a mediating variable rather than a direct predictor of sport commitment. Although not statistically more predictive than the model developed by Scanlan et al. (1993), Weiss and colleagues (2001) suggested that enjoyment could be conceived as a partial mediator in conceptualizing sport commitment. Both models support the contention that enjoyment plays an important role in youth's decision to participate in sport for an extended period of time. What is less clear is how an individual's enjoyment levels influence youth experience in sports.

Motivational climate is another important factor that is known to influence participation in sport (Balaguer, Duda, \& Crespo, 1999; Duda \& Balaguer, 2007; Smith, Smoll, \& Cumming, 2007). Operationalized as either task or ego, motivational climate reflects an individual's perception of the sport setting. A task climate is created when the focus is on personal skill development regardless of how others perform. Conditions where coaches and/or peers encourage athletes to give their best effort in attaining challenging but realistic goals facilitate a task oriented climate. Alternatively, an ego climate is formed when the focus is on demonstrating superior ability over others (Smith et al., 2007). In general, research on motivational climate suggests that a task climate has a positive effect on athletes while an ego climate results in negative sport experiences (Duda \& Balaguer, 2007). In a study investigating the effects of a motivational climate intervention with coaches on athlete anxiety levels, Smith et al. (2007) found that athletes who played for coaches who received task climate training decreased in anxiety throughout the season. Athletes who played for coaches who did not receive any training increased 
in anxiety as the season progressed. Balaguer et al. (1999) investigated perceptions of motivational climate on satisfaction and coach ratings in a group of 219 tennis players and found that task climate was linked to increased perceptions of ability to use psychological skills, satisfaction with level of play, and match results. Their results were corroborated by Cumming, Smoll, Smith, and Grossbard (2007) who found that a task climate was significantly related to an athlete's satisfaction with the coach. Cumming et al. also found that a task climate was related to win-loss records and enjoyment. Alternatively, perceptions of an ego climate are associated with negative experiences such as peer conflict (Ommundsen, Roberts, Lemyre, \& Miller, 2005), negative perceptions of the coach (Smith, Fry, Ethington, \& Li, 2005), and increased anxiety (Pensgaard \& Roberts, 2002). Overall, these studies suggest that a task oriented motivational climate is beneficial for sport participation while an ego climate can reduce participation in youth.

While the above research studies pertaining to enjoyment and motivational climate are largely framed around sport participation, it has been suggested that another primary goal of youth sport programs should be personal development (Côté \& Fraser-Thomas, 2007). Authors argue that a properly structured youth sport program is an ideal setting in which youth can learn valuable skills that can be applied to other facets of their lives (Fraser-Thomas, Côté, \& Deakin, 2005; Petitpas, Cornelius, Van Raalte, \& Jones, 2005). Hansen and colleagues (Hansen \& Larson, 2007; Hansen, Larson, \& Dworkin, 2003; Larson, Hansen, \& Moneta, 2006) tested this assumption with a series of studies that examined the experiences of youth in different structured activities (i.e., sports, arts, faith groups, academic programs, community groups). Hansen et al. (2003) found that sport participants and faith groups developed higher emotional regulation than academic groups. They also found that sport participants reported higher rates of negative peer interactions than faith, academic, and arts groups and that inappropriate adult behaviors were higher in sports than in faith groups. In another study of 228011 th grade youth who participated in the same activities outlined above, Larson et al. (2006) found that sport participants reported higher rates of goal setting and effort; however athletes also reported higher levels of the negative experiences of stress and social exclusion compared with other activities.

A more recent study by Strachan, Côté, and Deakin (2009) assessed positive and negative personal development between groups of athletes aged 12-16 years who sample (athletes who participate in multiple sports) or specialize (athletes heavily invested in only one sport). They found that athletes in the sampling group reported stronger links to their sport, family, and community, whereas specializers reported higher rates of diverse peer groups, but also higher rates of physical and emotional exhaustion. These results demonstrate that participation in sport is related to a range of positive and negative developmental experiences.

Given that enjoyment and motivational climate are established predictors of sport participation, they may also be useful in predicting other youth sport outcomes such as positive and negative personal development. However, these relationships have yet to be investigated. One possible explanation for the lack of research on this topic is the shortage of tools available to measure personal development in sport participants. Until recently, a personal development measure designed specifically for sport participants had yet to be developed. MacDonald, Deakin, Eys, and Côté (2009) created the Youth Experiences Survey for Sport (YES-S) by modifying the 
more general Youth Experience Survey (YES; Hansen \& Larson, 2002; 2005). The YES-S is a 37-item scale that measures positive and negative personal development of sport participants on the five dimensions of personal and social skills, cognitive skills, goal setting, initiative, and negative experiences. As a result, the purpose of the current study was to examine the effects of enjoyment and motivational climate on the personal development of youth sport participants. Hypotheses were that higher reports of enjoyment and task climate would be associated with positive personal development experiences and that higher reports of an ego climate would be associated with greater negative experiences.

\section{Method}

\section{Participants}

The participants in the study were 510 male $(47.5 \%)$ and female $(52.5 \%)$ athletes between the ages of 9 and 19 years $(M=14.88, S D=1.58)$. Athletes participated in school sports or nonelite community programs across the sports of baseball (9), basketball (68), curling (6), dance (29), football (55), hockey (132), lacrosse (13), ringette (11), rowing (2), soccer (99), softball (20), synchronized swimming (10), and volleyball (56). A diverse sample of team sports was used to provide a wide range of possible experiences. The sample was limited to team sports given that motivational climate reflects individual perceptions of group atmosphere. The operational definition used in the current study to represent team sports was that athletes practice and compete as a group.

\section{Measures}

Youth Experience Survey for Sport. Positive and negative personal development experiences were assessed using the Youth Experience Survey for Sport (YESS; MacDonald et al., 2009). The YES-S was developed from a modified version of the Youth Experience Survey 2.0 (YES; Hansen \& Larson, 2005) in a group of 637 youth sport participants. The YES-S is a 37 -item questionnaire that measures personal development experiences of youth sport participants on the five dimensions of personal and social skills (14 items; i.e., "I became better at giving feedback"), cognitive skills (5 items; i.e., "this activity increased my desire to stay in school"), goal setting (4 items; i.e., "I set goals for myself in this activity"), initiative (4 items; i.e., "I put all my energy into this activity"), and negative experiences (10 items; i.e., "I got stuck doing more than my fair share"). Athletes reflect on their current or recent sport involvement in a given setting and respond to each statement using a 4-point Likert-type scale anchored by 'Not at all' to 'Yes definitely' as representing experiences that occurred during their sport involvement. The instrument has shown acceptable psychometric properties with values of $Q=2.32, \mathrm{CFI}=.91$, and RMSEA $=.06$ (MacDonald et al., 2009). Reliability analyses of the subscales in the current study produced Cronbach alpha values between .79 and .90 .

Sources of Enjoyment in Youth Sport Questionnaire. The second measure used was the Sources of Enjoyment in Youth Sport Questionnaire (SEYSQ; Wiersma, 
2001). The SEYSQ is a 28 -item scale that measures enjoyment on the six dimensions of self-referenced competency (4 items; i.e., "playing well compared to how I've played in the past"), other-referenced competency and recognition (6 items; i.e., "being better in my sport than other athletes my age or in my league"), effort expenditure (5 items; i.e., "playing hard during competition"), competitive excitement (4 items; i.e., "the excitement of competition"), affiliation with peers (5 items; i.e., "being with friends on my team"), and positive parental involvement (4 items; i.e., "getting support from my parent(s) for playing my sport"). Each statement is preceded by the stem "During the times when I most enjoy sport, I usually experience that enjoyment from ...". Responses on the SEYSQ are given using a 5-point Likert-type scale that ranges from 'Not at all' to 'Very much'. The six-factor structure of the SEYSQ has been validated by Wiersma (2001) with a sample of 896 young athletes between the ages of 12 and 18 years. Results of the confirmatory factor analysis demonstrated good fit parameters with a RMSEA = .05 and a CFI $=.97$. Reliability analyses demonstrated acceptable values ranging between .65 and .85 . In the current study, reliability coefficients for the different subscales of the SEYSQ were between .74 and .84 .

Motivational Climate Scale for Youth Sport. The final measure used was the Motivational Climate Scale for Youth Sport (MCSYS; Smith, Cumming, \& Smoll, 2008). The instrument was developed with 992 young athletes between the ages of 9 and 16 years and measures two dimensions of motivational climate (task and ego) present in the youth sport domain. The two factor model tested by Smith et al. (2008) demonstrated strong psychometric properties with values of $Q=1.52$, $\mathrm{CFI}=.97, \mathrm{GFI}=.97$, and RMSEA $=.04$. Specifically, the MCSYS asks athletes to rate 12 statements related to the sport climate on a 1 (Not at all true) to 5 (Very true) Likert-type scale. Six statements are linked to a task climate while six are related to an ego climate. In the current study, task and ego subscales showed reliability coefficients of .82 and .79 respectively.

\section{Procedure}

Data were collected from community sport programs and high schools located in the province of Ontario, Canada. Following university ethics approval, sport programs and high schools were contacted for participation in the study. When a school or program agreed to participate, arrangements were made to secure a time during which data collection could occur.

For the athletes in the schools, data collection occurred during a designated class time. Before data collection, letters of information and consent were sent home with students. A research assistant then proceeded with the data collection phase with students who agreed to participate. Athletes were given the opportunity to withdraw from the study on the day of data collection if they did not want to participate. The students who agreed to participate were given instructions about the purpose of the study and asked to fill out each questionnaire with their primary sport in mind. These instructions allowed athlete's to choose the sport in which they were most involved and reflect on the experiences that occurred in that environment. Any questions that came up during data collection were addressed immediately. All questionnaires were completed during the designated time and collected by the 
research assistant. The time needed for participants to complete the questionnaires was approximately $30-40 \mathrm{~min}$.

Once sport teams agreed to participate, a meeting time was arranged to explain the purpose of the study and provide athletes the opportunity to complete the questionnaires. This meeting typically occurred at the end of a practice or game. During this meeting, the purpose was explained and appropriate documentation was provided to the participants. Participation was voluntary and athletes could withdraw at any moment without consequence. A copy of each questionnaire, letter of information, and consent/assent forms were distributed to athletes who agreed to participate. Each participant was encouraged to complete the questionnaires on location however some could not commit the 30-40 min required to complete the forms and completed the questionnaires at home. When athletes completed the questionnaire at home, the primary researcher returned after a subsequent practice or game to collect the completed documents. Athletes returned the completed questionnaires to the primary researcher in a sealed envelope. Only a small number of athletes were unable to commit the time required to complete the questionnaires and chose to not participate in the study.

\section{Data Analysis}

Data were entered into a spreadsheet and cleaned to contain only valid cases. In some instances participants did not complete all the questionnaires; these individuals were subsequently removed from the analysis due to large amounts of missing data. For other missing data, a pairwise deletion method was employed. This method removes individual cases in the variable of interest. A research assistant double checked the data for entry errors. With incomplete cases removed, normality and homoscedasticity were assessed across variables of interest. No variables had to be recoded due to nonnormal or heteroscedastic patterns.

Stepwise multiple regression analysis was used to assess the relationships between subscales of the SEYSQ and MCSYS on personal development as outlined by the YES-S. Stepwise regression was selected over other approaches because the relationships between experiences, enjoyment, and motivational climate have yet to be established. Therefore, a method which builds a model was preferred over a method that tests a model (Tabachnick \& Fidell, 2007). Five separate models using each subscale of the YES-S as the dependent variable tested the relationships.

\section{Results}

Mean and standard deviation values for each subscale with corresponding reliability coefficients are presented in Table 1. Mean values of the YES-S demonstrate that youth experiences were quite positive but that athletes also faced negative experiences. The climate in which these activities took place were mainly task oriented and athletes reported high levels of enjoyment on all subscales. Reliability analyses of the YES-S, MCSYS and SEYSQ showed acceptable values for each of the subscales. Inspection of correlations between subscales of the SEYSQ and MCSYS showed low to moderate relationships with Pearson coefficients between -.30 and .63 (Table 2). 
Table 1 Descriptive Statistics and Cronbach Reliability Coefficients of the YES-S, MCSYS, and SEYSQ Subscales

\begin{tabular}{lccc}
\hline & M & $S D$ & $\alpha$ \\
\hline Youth Experience Survey for Sport ${ }^{\mathrm{a}}$ & & & \\
Personal and social skills & 2.98 & .63 & .90 \\
Cognitive skills & 2.26 & .87 & .84 \\
Goal setting & 3.06 & .69 & .81 \\
Initiative & 3.47 & .56 & .79 \\
Negative experiences & 1.71 & .79 & .93 \\
Motivational Climate Scale for Youth Sport ${ }^{\mathrm{b}}$ & & & \\
Task climate & & .71 & .82 \\
Ego climate & 4.11 & .71 \\
Sources of Enjoyment in Youth Sport Questionnaire ${ }^{\mathrm{b}}$ & & .86 & .79 \\
Self-referenced competency & 2.24 & & \\
Other-referenced competency & 4.24 & .65 & .74 \\
Effort expenditure & 3.52 & .94 & .85 \\
Competitive excitement & & .75 & .79 \\
Affiliation with peers & & .79 \\
Positive parental involvement & 4.03 & .86 & .84 \\
\hline
\end{tabular}

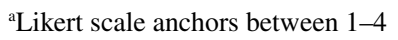

${ }^{b}$ Likert scale anchors between $1-5$

The personal development of athletes was investigated using stepwise multiple regressions. Five models, using each subscale of the YES-S as a dependent variable, were tested with two subscales of the MCSYS and six subscales of the SEYSQ as independent variables to determine which predicted positive and negative personal development. Results of the models are presented in Table 3.

\section{Personal and Social Skills}

Five variables significantly predicted personal and social skills. The strongest predictor, which explained approximately $27 \%$ of the variance, was affiliation with peers. The variables of effort expenditure, task climate, competitive excitement, and ego climate also predicted personal and social skills and accounted for an additional 


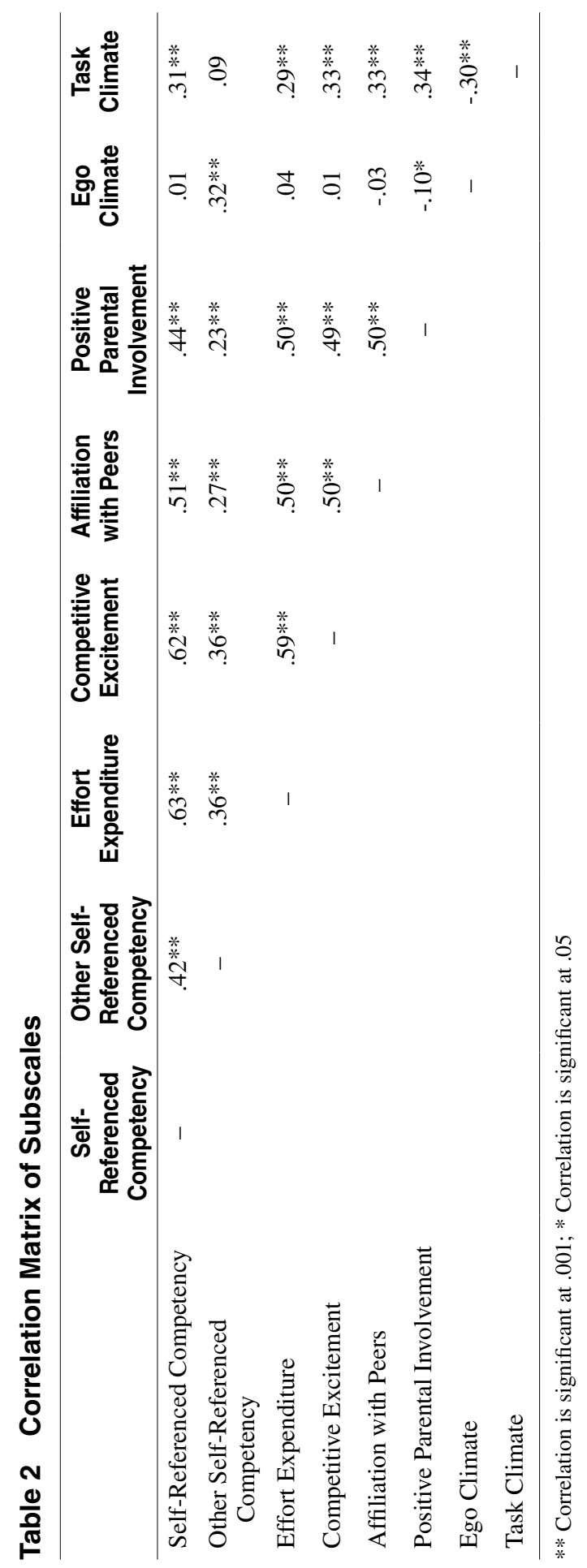


Table 3 Stepwise Multiple Regression Analyses Predicting the YES-S Subscales

\begin{tabular}{|c|c|c|c|c|}
\hline YES-S subscales & Significant predictors & $M S$ & B & $r^{2}$ \\
\hline \multirow{5}{*}{$\begin{array}{l}\text { Personal and } \\
\text { social skills }\end{array}$} & Affiliation with peers & 54.61 & .27 & .27 \\
\hline & Effort expenditure & 33.84 & .18 & .34 \\
\hline & Task climate & 23.93 & .15 & .36 \\
\hline & Competitive excitement & 18.37 & .10 & .37 \\
\hline & Ego climate & 14.92 & .06 & .37 \\
\hline \multirow[t]{3}{*}{ Cognitive skills } & Other-referenced competency & 34.43 & .25 & .09 \\
\hline & Effort expenditure & 23.14 & .33 & .12 \\
\hline & Self-referenced competency & 17.63 & -.23 & .14 \\
\hline \multirow[t]{4}{*}{ Goal setting } & Self-referenced competency & 46.96 & .23 & .19 \\
\hline & Affiliation with peers & 29.21 & .18 & .24 \\
\hline & Task climate & 20.80 & .13 & .25 \\
\hline & Effort expenditure & 16.31 & .13 & .27 \\
\hline \multirow[t]{4}{*}{ Initiative } & Competitive excitement & 35.43 & .19 & .22 \\
\hline & Effort expenditure & 20.60 & .12 & .26 \\
\hline & Task climate & 14.86 & .11 & .28 \\
\hline & Self-referenced competency & 11.56 & .12 & .29 \\
\hline \multirow{4}{*}{$\begin{array}{l}\text { Negative } \\
\text { experiences }\end{array}$} & Ego climate & 28.84 & .20 & .09 \\
\hline & Other-referenced competency & 19.25 & .21 & .12 \\
\hline & Self-referenced competency & 15.91 & -.33 & .15 \\
\hline & Effort expenditure & 12.92 & .15 & .16 \\
\hline
\end{tabular}

$10 \%$ of the variance. The relationship between the predictors and dependent variable were positive meaning that high scores on these scales led to higher reports of personal and social skills.

\section{Cognitive Skills}

Three variables significantly contributed to the explanation of cognitive skill development and accounted for approximately $14 \%$ of the variance. Other-referenced competency was the strongest predictor and accounted for approximately $9 \%$ of the variance in cognitive skills. Conceptualized as comparing one's ability to others, 
this result suggests that comparison between athletes is beneficial to the development of cognitive skills. Similarly, the construct of self-referenced competency, which is manifested through an individual's attainment of personal performance goals, was negatively related to the development of cognitive skills. Finally, high effort expenditure was positively related to the development of cognitive skills.

\section{Goal Setting}

Approximately $27 \%$ of the variability in goal setting was explained by four variables. Self-referenced competency, affiliation with peers, task climate, and effort expenditure were found to be positively related to goal setting behaviors. Self-referenced competency and task climate are complimentary concepts and deal with reaching one's potential by achieving personal performance benchmarks. Affiliation with peers and effort expenditure are two constructs that relate to goal setting. Team sport participants need to function as a unit and invest similar amounts of effort to reach their goals. The results of this model suggest that high levels of connectedness with peers and higher effort during an activity leads to more opportunities for goal setting.

\section{Initiative}

Four variables (competitive excitement, effort expenditure, task climate, and selfreferenced competency) combined to explain approximately $29 \%$ of the variance in initiative. Experiencing enjoyment from upcoming competitions explained the most variance in initiative with $22 \%$. Similar to goal setting, effort expenditure, a task climate, and self-referenced competency combined to explain part of the variability in initiative.

\section{Negative Experiences}

Four variables predicted $16 \%$ of the variance in negative experiences. The strongest predictor of negative experiences was an ego climate. This result suggests that climates which place emphasis on evaluating ability based on outperforming others (i.e., winning) promote negative experiences in young athletes. Related to an ego climate, results indicate that having high scores on other-referenced competency also predict negative experiences. Considering that both these constructs are similar in nature, this result was not entirely surprising. Athletes who reported high levels of self-referenced competency showed lower rates of negative experiences.

\section{Discussion}

Across the positive domains of the YES-S, results identified affiliation with peers, effort expenditure, self-referenced competency, and task climate as the important predictors of personal development in youth sport participants. This supports the first hypothesis of this study by linking high rates of enjoyment and a task climate to positive personal development. Conversely an ego climate was found to be the strongest predictor of negative personal development, which supports the second hypothesis of the study. 


\section{Positive Personal Development}

The strongest predictor of personal and social skills was affiliation with peers. This suggests that creating opportunities for positive peer interactions in the sport domain is beneficial for the development of personal and social skills. This finding adds to our understanding of peer relationships in sport by demonstrating that positive relationships with peers are not only important for participation purposes (Smith, 2007; Weiss \& Williams, 2004) but can also lead to positive personal development in youth.

The benefit of establishing positive and strong relationships with peers may well be responsible for the finding of task and ego climates as positive contributors to the development of personal and social skills. This finding differs from previous work (Cumming et al. 2007; Duda \& Balaguer 2007) that links task climates with positive emotional and cognitive development in athletes and ego climates with negative development (for a review, see Duda \& Balaguer, 2007). Results also suggest that peer relationships within the sport setting play a larger role (Holt, Black, Tamminen, Fox, \& Mandigo, 2008) than the perceived climate, which would explain why personal and social skills developed across both task and ego climates. However, further investigations of the relationship between affiliation with peers and motivational climates are necessary to substantiate this claim.

Eccles and Barber (1999) linked sport participation with increased gradepoint average and subsequent college enrolment. The relationship between sport and school success suggests that processes within the sport environment help athletes develop cognitive abilities. The present study found that other-referenced competency and effort expenditure were positively related to cognitive skills while self-referenced competency was negatively related. These findings imply that comparison with others and effort relates to greater cognitive skill development than other aspects of enjoyment and motivational climate. Although it is unclear why this is the case, it is possible that other-referenced competency and effort serve as moderating variables between participation in sport and a child's cognitive development. In addition, it is unclear if the findings of this study would be supported for youth who participate in different structured activities such as arts or faith-based programs. It would be worthwhile for future studies to examine the relationship between comparisons to others and cognitive development across different domains to further understand the role of structured activities on cognitive development.

Approximately $25 \%$ of the variance in goal setting was explained by positive reports of self-referenced competency, affiliation with peers, and task climate. It is believed that the predictors of goal setting identified in this study reflect how athletes use individual and team goals in the sport environment (Dawson, Bray, \& Widmeyer, 2002). Individual goals reflect self-referenced competency and can be used to set personal standards of performance or desired outcomes of sport participation (Burton \& Weiss, 2008). Team goals, which are related to affiliation with peers, are important for team success (Prapavessis, Carron, \& Spink, 1996) and should be used by coaches and teams to set performance standards. The present results suggest that goal setting behaviors can be enhanced by creating a task-oriented environment that stresses positive affiliation with peers and self-referenced competency.

Applications of goal setting behaviors in youth sport programs were related to the personal development of children. Danish and colleagues (Danish, Forneris, 
Hodge, \& Heke, 2004; Danish, Forneris, \& Wallace, 2005) developed Sports United to Promote Education and Recreation (SUPER; see Danish, Fazio, Nellen, \& Owen, 2002); a program which teaches youth sport participants a number of life skills within the sport setting by providing workshops to participants. Of the 18 workshops that makeup the SUPER program, seven deal with goal setting and discuss how goals are created/reached in sport and in other aspects of life (Danish et al., 2005). Brunelle, Danish, and Forneris (2007) assessed the impact of the SUPER program on adolescent development and found that the program had a positive effect on youth's prosocial behavior and social responsibility. Although the impact of goal setting modules was not teased out, their results support the findings of this study and identify goal setting as a component of personal development.

Competitive excitement, effort expenditure, task climate, and self-referenced competency were positively related to the construct of initiative. This demonstrates that initiative can be developed in sport by creating an environment that promotes excitement, effort expenditure, and self-referenced competency within a task climate. Coaches and sport programs interested in the development of initiative in youth should consider these factors if they want to create an environment consistent with principles of positive youth development through sport. Larson (2000) argues that youth will develop initiative if they are intrinsically motivated, invest high amount of effort in the activity, and participate over time. The strongest predictor of initiative, which is competitive excitement, shares similarities with intrinsic motivation. Scanlan and Lewthwaite (1986) argue that enjoyment and intrinsic motivation are related and require athletes to develop positive perceptions of competence before an activity is deemed enjoyable and intrinsically motivating. Given the connection between enjoyment and intrinsic motivation, the present results suggest that increased enjoyment may have a role in the development of initiative. Another predictor of initiative is effort expenditure. This construct reflects Larson's (2000) notion of investing high amounts of energy in the activity. Given that athletes typically participate in sport for an extended period of time (i.e., at least one season), the current predictive model supports the three conditions identified by Larson (2000) for the development of initiative.

\section{Negative Personal Development}

The strongest predictors of negative personal development were an ego climate and other-referenced competency. This result suggests that focusing one's attention on comparison with others rather than personal achievement will increase negative experiences in the sport domain. The link between ego climates and negative sport experiences is well documented (Balaguer et al., 1999; Cumming et al., 2007; Smith et al., 2008; Vazou, Ntoumanis, \& Duda, 2006) and implies that an environment emphasizing comparisons with others leads to higher rates of negative experiences. Although an ego climate was found to be a positive predictor of personal and social skill development, it is recommended that ego climates be implemented with caution as results point to negative experiences as an additional outcome of ego climates. In contrast, self-referenced competency was negatively related to negative experiences meaning that environments which focus on mastery of skills and personal achievement can reduce negative experiences in youth. 


\section{Summary and Conclusion}

The results of this study are important for understanding the positive and negative personal development of young athletes; however limitations exist. The relationships were found in team sport athletes and may not necessarily reflect the personal development of individual sport athletes. For example, it is possible that affiliation with peers is not a significant predictor of goal setting in individual sports. Future research is needed to understand how motivational climate and enjoyment affect personal development across individual and team sports. A second limitation is that total weekly involvement in sport programs was not taken into account. It is possible that differences exist between athletes who invest more time in their program compared with athletes who spend less time. Analyses of how much time spent in the sport affects personal development is an interesting avenue of future investigation. A third limitation deals with the age of the participants in the sample. Although a wide age range was collected, it is unclear if athletes of different ages had differing personal development experiences. Investigations of how personal development differs across athletes of different ages would be important to investigate in future studies. Finally, due to a lack of statistical power, the analyses used in this study did not account for individuals being nested within teams. Future studies that collect data from teams should collect a sufficiently large sample size to use multilevel modeling techniques and account for individual and program level variables (Tabachnick \& Fidell, 2007).

The findings of the current study identify affiliation with peers, effort expenditure, self-referenced competency, and task climate as the most important predictors of personal development in young athletes. Research on motivational climate and enjoyment has linked these constructs to sport participation (Duda \& Balaguer, 2007; Weiss \& Williams, 2004); however their impact on the personal development of youth was unknown. The findings strengthen the understanding of how personal development can be increased within the youth sport domain and suggest that sport programs and coaches who wish to increase the personal development of athletes consider these factors and incorporate them into their sport environment. This can be achieved by fostering an environment of personal success by promoting the use of personal achievement goals within the sport setting. Creating an environment that focuses on the child reflects the factors of task climate and self-referenced competency. In addition, if athletes are encouraged to share their goals with others and support each other in achieving them, stronger peer relationships and increased motivation to participate may ensue, which are important factors identified as predictors of the personal development of young athletes.

\section{References}

Balaguer, I., Duda, J.L., \& Crespo, M. (1999). Motivational climate and goal orientations as predictors of perceptions of improvement, satisfaction, and coach ratings among tennis players. Scandinavian Journal of Medicine \& Science in Sports, 9, 381-388.

Brunelle, J., Danish, S.J., \& Forneris, T. (2007). The impact of a sport-based life skill program on adolescent prosocial values. Applied Developmental Science, 11, 43-55.

Burton, D., \& Weiss, C. (2008). The fundamental goal concept: The path to process and performance success. In T.S. Horn (Ed.), Advances in sport psychology (3rd ed., pp. 339-375). Champaign, IL: Human Kinetics. 
Côté, J., \& Fraser-Thomas, J. (2007). Youth involvement in sport. In P. Crocker (Ed.), Sport psychology: A Canadian perspective (pp. 266-294). Toronto: Pearson.

Cumming, S.P., Smoll, F.L., Smith, R.E., \& Grossbard, J.R. (2007). Is winning everything? The relative contribution of motivational climate and won-loss percentage in youth sport. Journal of Applied Sport Psychology, 19, 322-336.

Danish, S.J., Fazio, R.J., Nellen, V.C., \& Owen, S.S. (2002). Teaching life skills through sport: Community-based programs to enhance adolescent development. In J.L. Van Raalte \& B.W. Brewer (Eds.), Exploring sport and exercise psychology (2nd ed., pp. 269-288). Washington, DC: American Psychological Association.

Danish, S.J., Forneris, T., Hodge, K., \& Heke, I. (2004). Enhancing youth development through sport. World Leisure, 3, 38-49.

Danish, S.J., Forneris, T., \& Wallace, I. (2005). Sport-based life skills programming in the schools. Journal of Applied School Psychology, 21, 41-62.

Dawson, K.A., Bray, S.R., \& Widmeyer, W.N. (2002). Goal setting by intercollegiate sport teams and athletes. Avante, 8, 14-23.

Duda, J.L., \& Balaguer, I. (2007). Coach-created motivational climate. In S. Jowett \& D. Lavallee (Eds.), Social psychology in sport (pp. 117-130). Champaign, IL: Human Kinetics.

Eccles, J.S., \& Barber, B.L. (1999). Student council, volunteering, basketball, or marching band: What kind of extracurricular involvement matters? Journal of Adolescent Research, 14, 10-43.

Fraser-Thomas, J.L., Côté, J., \& Deakin, J. (2005). Youth sport programs: An avenue to foster positive youth development. Physical Education and Sport Pedagogy, 10, 19-40.

Guèvremont, A., Findlay, L., \& Kohen, D. (2008). Organized extracurricular activities of Canadian children and youth. Health Reports, 19, Statistics Canada, Catalogue no. 82-003-XPE.

Hansen, D.M., \& Larson, R. (2002). The Youth Experience Survey 1.0: Instrument development and testing. Unpublished manuscript, University of Illinois at Urbana-Champaign. [http://web.aces.uiuc.edu/youthdev/].

Hansen, D.M., \& Larson, R. (2005). The Youth Experience Survey 2.0: Instrument revisions and validity testing. Unpublished manuscript, University of Illinois at UrbanaChampaign. [http://web.aces.uiuc.edu/youthdev/].

Hansen, D.M., \& Larson, R.W. (2007). Amplifiers of developmental and negative experiences in organized activities: Dosage, motivation, lead roles, and adult-youth ratios. Journal of Applied Developmental Psychology, 28, 360-374.

Hansen, D.M., Larson, R.W., \& Dworkin, J.B. (2003). What adolescents learn in organized youth activities: A survey of self-reported developmental experiences. Journal of Research on Adolescence, 13, 25-55.

Holt, N.L., Black, D.E., Tamminen, K.A., Fox, K.R., \& Mandigo, J.L. (2008). Levels of social complexity and dimensions of peer experiences in youth sport. Journal of Sport \& Exercise Psychology, 30, 411-431.

Larson, R.W. (2000). Toward a psychology of positive youth development. The American Psychologist, 55, 170-183.

Larson, R.W., Hansen, D.M., \& Moneta, G. (2006). Differing profiles of developmental experiences across types of organized youth activities. Developmental Psychology, 42, 849-863.

MacDonald, D.J., Deakin, J., Eys, M., \& Côté, J. (2009). Psychometric properties of the Youth Experience Survey with young athletes. Paper presented at the Canadian Society for Psychomotor Learning and Sport Psychology, Toronto, ON.

Mahoney, J.L., Larson, R.W., Eccles, J.S., \& Lord, H. (2005). Organized activities as developmental contexts for children and adolescents. In J.L. Mahoney, R.W. Larson, \& J.S. Eccles (Eds.), Organized activities as contexts of development (pp. 3-22). Mahwah, NJ: Lawrence Erlbaum Associates. 
Ommundsen, Y., Roberts, G.C., Lemyre, P.N., \& Miller, B.W. (2005). Peer relationships in adolescent competitive soccer: Associations to perceived motivational climate, achievement goals and perfectionism. Journal of Sports Sciences, 23, 977-989.

Pate, R.R., Trost, S.G., Levin, S., \& Dowda, M. (2000). Sport participation and healthrelated behaviors among US youth. Archives of Pediatrics \& Adolescent Medicine, 154, 904-911.

Pensgaard, A.M., \& Roberts, G.C. (2002). Elite athletes' experiences of the motivational climate: The coach matters. Scandinavian Journal of Medicine \& Science in Sports, $12,54-59$.

Petitpas, A.J., Cornelius, A.E., Van Raalte, J.L., \& Jones, T. (2005). A framework for planning youth sport programs that foster psychosocial development. The Sport Psychologist, 19, 63-80.

Prapavessis, H., Carron, A.V., \& Spink, K.S. (1996). Team building in sport. International Journal of Sport Psychology, 27, 269-285.

Scanlan, T.K., Carpenter, P.J., Schmidt, G.W., Simons, J.P., \& Keeler, B. (1993). An introduction to the sport commitment model. Journal of Sport \& Exercise Psychology, 15, 1-15.

Scanlan, T.K., \& Lewthwaite, R. (1986). Social psychological aspects of competition for male youth sport participants: IV. Predictors of enjoyment. Journal of Sport Psychology, 8, 25-35.

Scanlan, T.K., Stein, G.L., \& Ravizza, K. (1989). An in-depth study of former elite figure skaters: II. Sources of enjoyment. Journal of Sport \& Exercise Psychology, 11, 65-83.

Smith, A.L. (2007). Youth peer relationships in sport. In S. Jowett \& D. Lavallee (Eds.), Social psychology in sport (pp. 41-54). Champaign, IL: Human Kinetics.

Smith, R.E., Cumming, S.P., \& Smoll, F.L. (2008). Development and validation of the motivational climate scale for youth sport. Journal of Applied Sport Psychology, 20, 116-136.

Smith, R.E., Smoll, F.L., \& Cumming, S.P. (2007). Effects of a motivational climate intervention for coaches on young athletes' sport performance anxiety. Journal of Sport \& Exercise Psychology, 29, 39-59.

Smith, S.L., Fry, M.D., Ethington, C.A., \& Li, Y. (2005). The effect of female athletes' perceptions of their coaches' behavior on their perceptions of motivational climate. Journal of Applied Sport Psychology, 17, 170-177.

Strachan, L., Côté, J., \& Deakin, J. (2009). "Specializers" versus "Samplers" in youth sport: Comparing experiences and outcomes. The Sport Psychologist, 23, 77-92.

Tabachnick, B.G., \& Fidell, L.S. (2007). Using multivariate statistics (5th ed.). Boston, MA: Pearson Education Inc.

Vazou, S., Ntoumanis, N., \& Duda, J.L. (2006). Predicting young athletes' motivational indices as a function of their perceptions of the coach- and peer-created climate. Psychology of Sport and Exercise, 7, 215-233.

Weiss, M.R., Kimmel, L.A., \& Smith, A.L. (2001). Determinants of sport commitment among junior tennis players: Enjoyment as a mediating variable. Pediatric Exercise Science, 13, 131-144.

Weiss, M.R., \& Williams, L. (2004). The why of youth sport involvement: A developmental perspective on motivational processes. In M.R. Weiss (Ed.), Developmental sport and exercise psychology: A lifespan perspective (pp. 223-268). Morgantown, WV: Fitness Information Technology Inc.

Wiersma, L.D. (2001). Conceptualization and development of the Sources of Enjoyment in Youth Sport Questionnaire. Measurement in Physical Education and Exercise Science, 5, 153-177. 